\title{
Echocardiographic parameters during prolonged targeted temperature Management in out-of-hospital Cardiac Arrest Survivors to predict neurological outcome - a post-hoc analysis of the TTH48 trial
}

Thomas Hvid Jensen ${ }^{1 *}$, Peter Juhl-Olsen², Bent Roni Ranghøj Nielsen³, Johan Heiberg ${ }^{4}$,

Christophe Henri Valdemar Duez ${ }^{5}$, Anni Nørgaard Jeppesen ${ }^{6}$, Christian Alcaraz Frederiksen ${ }^{3}$, Hans Kirkegaard ${ }^{7}$ and Anders Morten Grejs ${ }^{2}$

\begin{abstract}
Background: Transthoracic echocardiographic (TTE) indices of myocardial function among survivors of out-ofhospital cardiac arrest (OHCA) have been related to neurological outcome; however, results are inconsistent. We hypothesized that changes in average peak systolic mitral annular velocity (s') from $24 \mathrm{~h}$ ( $\mathrm{h}$ ) to $72 \mathrm{~h}$ following start of targeted temperature management (TTM) predict six-month neurological outcome in comatose OHCA survivors.

Methods: We investigated the association between peak systolic velocity of the mitral plane (s') and six-month neurological outcome in a population of 99 patients from a randomised controlled trial comparing $T \mathrm{M}$ at $33 \pm 1{ }^{\circ} \mathrm{C}$ for $24 \mathrm{~h}(\mathrm{~h})(n=47)$ vs. $48 \mathrm{~h}(n=52)$ following OHCA (TTH48-trial). TTE was conducted at $24 \mathrm{~h}, 48 \mathrm{~h}$, and $72 \mathrm{~h}$ after reaching target temperature. The primary outcome was 180 days neurological outcome assessed by Cerebral Performance Category score (CPC180) and the primary TTE outcome measure was s'. Secondary outcome measures were left ventricular ejection fraction (LVEF), global longitudinal strain (GLS), e', E/e' and tricuspid annular plane systolic excursion (TAPSE).
\end{abstract}

Results: Across all three scan time points s' was not associated with neurological outcome (ORs: $24 \mathrm{~h}: 1.0$ (95\%Cl: $0.7-1.4, p=0.98), 48 \mathrm{h:} 1.13$ (95\%Cl: 0.9-1.4, $p=0.34$ ), $72 \mathrm{h:} 1.04$ (95\%Cl: 0.8-1.4, $p=0.76)$ ). LVEF, GLS, E/e', and TAPSE recorded on serial TTEs following OHCA were neither associated with nor did they predict CPC180. Estimated median e' at $48 \mathrm{~h}$ following TTM was $5.74 \mathrm{~cm} / \mathrm{s}$ (95\%Cl: 5.27-6.22) in patients with good outcome (CPC180 1-2) vs. $4.95 \mathrm{~cm} / \mathrm{s}(95 \% \mathrm{Cl}: 4.37-5.54)$ in patients with poor outcome (CPC180 3-5) $(p=0.04)$.

(Continued on next page)

\footnotetext{
* Correspondence: thomashvidjensen@gmail.com

'Department of Cardiology, Viborg Regional Hospital, Heibergs Alle 2K, 8800 Viborg, Denmark

Full list of author information is available at the end of the article
}

C C The Author(s). 2021 Open Access This article is licensed under a Creative Commons Attribution 4.0 International License, which permits use, sharing, adaptation, distribution and reproduction in any medium or format, as long as you give appropriate credit to the original author(s) and the source, provide a link to the Creative Commons licence, and indicate if changes were made. The images or other third party material in this article are included in the article's Creative Commons licence, unless indicated otherwise in a credit line to the material. If material is not included in the article's Creative Commons licence and your intended use is not permitted by statutory regulation or exceeds the permitted use, you will need to obtain permission directly from the copyright holder. To view a copy of this licence, visit http://creativecommons.org/licenses/by/4.0/. The Creative Commons Public Domain Dedication waiver (http://creativecommons.org/publicdomain/zero/1.0/) applies to the data made available in this article, unless otherwise stated in a credit line to the data. 


\begin{abstract}
(Continued from previous page)
Conclusions: $\mathrm{s}^{\prime}$ assessed on serial TTEs in comatose survivors of OHCA treated with TTM was not associated with

CPC180. Our findings suggest that serial TTEs in the early post-resuscitation phase during TTM do not aid the prognostication of neurological outcome following OHCA.
\end{abstract}

Trial registration: NCT02066753. Registered 14 February 2014 - Retrospectively registered,

Keywords: Cardiac arrest, Out-of-hospital cardiac arrest, Echocardiography, Targeted temperature management, Prognostication

\section{Introduction}

Worldwide, out-of-hospital cardiac arrest (OHCA) remains a major challenge with estimated survival to hospital discharge of $7-10 \%[1,2]$. More than $87 \%$ of inhospital deaths are due to brain injury or cardiac failure [3]. Following return of spontaneous circulation (ROSC), post-cardiac arrest syndrome and thus post-cardiac arrest myocardial dysfunction (PCAMD) contribute to cardiac failure and mortality [4]. PCAMD is characterised by global stunning of the ventricular function despite normal coronary blood flow $[5,6]$. Ventricular dysfunction is present in the first hours (h) following ROSC and often normalises within the following 24-72 $\mathrm{h}[5,7,8]$. Most previously studied transthoracic echocardiographic (TTE) indices such as left ventricular ejection fraction (LVEF) are prone to poor image quality and may overestimate left ventricular systolic function [9].

Targeted temperature management (TTM) for comatose survivors of cardiac arrest has been shown to improve survival and neurological outcome $[10,11]$ and is recommended by the International Liaison Committee on Resuscitation (ILCOR) as a post-cardiac arrest treatment for non-responsive survivors of OHCA [12]. The Targeted Temperature Management for 48 vs. 24 Hours and Neurologic Outcome After Out-of-Hospital Cardiac Arrest Trial (TTH48-trial) evaluated the effect of prolonged TTM at $33{ }^{\circ} \mathrm{C}$ for $48 \mathrm{~h}$ (TTM48) vs. $24 \mathrm{~h}$ (TTM24) following OHCA and found no difference in six-month neurological outcome or survival between groups [13]. In a substudy from TTH48, we showed a significant beneficial effect of $33^{\circ} \mathrm{C}$ TTM 48 on left ventricular longitudinal myocardial function, assessed as peak systolic mitral annular velocity (s'), when compared with TTM24 [14].

The association between PCAMD, mortality and neurological outcome has been investigated in several studies, and reduced LVEF has been related to poor neurological outcome and mortality following OHCA [15-18]. Furthermore, some studies have suggested that an elevated E/e' ratio is associated with in-hospital death and poor outcome following OHCA [19, 20]. However, results are inconsistent and existing studies lack methodological standardisation.

Our primary outcome Cerebral Performance Category $(\mathrm{CPC})$ is a five-point scale with high inter-observer agreement recognized in the Utstein Guidelines as an optimal tool for reporting of neurological outcome following cardiac arrest $[9,21]$. It is often dichotomized (CPC 1-2: good neurological outcome, CPC 3-5: poor neurological outcome) and widely used in previous studies of TTM in OHCA $[10,11,13]$.

Acquiring optimal echocardiographic imaging in immobilized intensive care unit (ICU) patients undergoing TTM is challenging, and to accompany this challenge s' was chosen as the primary echocardiographic measurement. s' has proven to be a reproducible measure of left ventricular longitudinal myocardial function relatively insensible to poor image quality $[22,23]$. Longitudinal fibres of the myocardium are situated in the sub endocardium making them prone to ischemic damage in case of significant coronary stenosis [24].

$\mathrm{s}^{\prime}$ is a strong predictor of mortality and adverse cardiovascular outcome following myocardial infarction independent of conventional echocardiographic findings $[25,26]$. Amongst patients with known left ventricular systolic dysfunction, s' is a predictor of cardiac death and hospitalization [27, 28]. However, whether changes in s' following OHCA is prognostic of poor neurological outcome (CPC 3-5) has yet to be evaluated.

In the present study, we aimed to evaluate if early changes in systolic and diastolic myocardial function predict neurological outcome in comatose OHCA survivors treated with TTM. We hypothesised that change in s' over time from $24 \mathrm{~h}$ to $72 \mathrm{~h}$ following start of TTM predicts the 180- day Cerebral Performance Category score (CPC180) [21] in comatose OHCA survivors treated with $33^{\circ} \mathrm{C}$ TTM for $24 \mathrm{~h}$ or $48 \mathrm{~h}$.

\section{Methods}

Study design

A sub-study of echocardiography data from 99 comatose OHCA survivors from the TTH48-trial was performed and the methods have been described in detail previously $[13,29]$. In brief, the study was conducted according to the Declaration of Helsinki and approved by the Danish Health Research Ethics Committee (file number 20110022). After written informed consent from a legal next of kin and the patient's general practitioner, patients were enrolled. Echocardiography data were 
obtained from 99 OHCA patients admitted to Aarhus University Hospital between February 2013 and July 2015.

The inclusion criteria were: comatose OHCA patients (Glasgow Coma Score $(\mathrm{GCS})<8$ ) with suspected cardiac origin, age from 18 to 80 years, and continuous sustained ROSC for $>20 \mathrm{~min}$.

Exclusion criteria were: $>60 \mathrm{~min}$ to ROSC, time from cardiac arrest to start of TTM $>4 \mathrm{~h}$, terminal illness, coagulopathy, unwitnessed arrest with asystole as first rhythm, pregnancy, persistent cardiogenic shock (systolic blood pressure $<80 \mathrm{mmHg}$ despite vasoactive treatment and/or aortic balloon pump intervention), CPC 3-4 prior to cardiac arrest, suspected intracerebral haemorrhage or stroke, acute coronary bypass grafting and/or lack of consent from a legal next of kin [22].

All prehospital data were collected using the Utstein Template [30]. According to the study protocol, all patients received $30 \mathrm{ml} / \mathrm{kg}$ isotonic saline at $4{ }^{\circ} \mathrm{C}$ prior to or at hospital admission.

At admission, significant coronary artery disease was diagnosed and treated according to guidelines, using emergency coronary angiography. In case of significant coronary artery disease, a percutaneous coronary intervention was performed.

\section{TTM intervention and randomisation}

Patients were sedated using intravenous infusions of propofol and remifentanil/fentanyl and mechanically ventilated with a target Richmond Agitation-Sedation Scale score of -5 [31]. Patients were cooled to a target temperature of $33 \pm 1 \mathrm{C}^{\circ}$ using either endovascular (ICY ${ }^{\circ}$ catheter, Thermogard XP, Zoll, US) or surface methods (Allon CureWrap , CritiCool, MTRE, Israel). From a urinary catheter (Coviden ${ }^{\mathrm{Tm}}$, Ireland), core temperature feedback was obtained to maintain target temperature. Cisatracurium was administered at TTM induction or if shivering occurred. Noradrenaline and/or inotropes were used if necessary to maintain mean arterial pressure > 60-65 mmHg. Patients were randomised online to TTM for 48 or $24 \mathrm{~h}$ using 1:1 randomisation with random block sizes within the first $23 \mathrm{~h}$ after admission. In the first $24 \mathrm{~h}$, diuretics and crystalloids were administered to maintain a urinary output of $>1 \mathrm{ml} / \mathrm{kg} / \mathrm{h}$. After cessation of TTM therapy, rewarming was initiated at a rate of $0.5^{\circ} \mathrm{C} / \mathrm{h}$.

\section{Echocardiography}

Two-dimensional (2D) transthoracic echocardiography images were obtained for offline analyses. A Vivid E9 scanner equipped with a $1.5-4.5 \mathrm{MHz}$ M5S phased array probe (GE Medical Systems Ultrasound, Norway) was used to record cine-loops at $24 \mathrm{~h}, 48 \mathrm{~h}$, and $72 \mathrm{~h}$ after reaching the target temperature. Echocardiography outcomes were averaged from three cycles in sinus rhythm and five cycles in atrial fibrillation. The primary outcome measure s' (average peak systolic mitral annular velocity) was obtained from colour tissue Doppler images (frame rate $>150$ frames/sec). In order to diminish the weakness of s' being insensible of global dysfunction, we improved our echocardiographic evaluation by scanning in three different left ventricular planes and measured mitral plane velocity in two regions of interest. s' was averaged from six different positions around the mitral valve (septal, lateral, anterior, inferior, anteriormedial, and inferior-lateral). Global longitudinal strain (GLS) was obtained from 2D greyscale images using speckle tracking (frame rate $50-80$ frames/sec) in the apical two-chamber, apical four-chamber, and apical long axis view. End of systole was defined as closure of the aortic valve. Biplane measurements were used to estimate LVEF with automatic speckle tracking (frame rate 50-80 frames/s). LVEF and GLS were used as secondary systolic outcome measures, and e' and E/e' were used as diastolic outcome measures [14]. Tricuspid annular plane systolic excursion (TAPSE) was used as outcome measure of right ventricular systolic function. Evaluation of the respiratory variability of the inferior vena cava (IVC) was applied as a surrogate marker of volume status. We used delta-IVC $(\triangle \mathrm{IVC})$ defined by maximum diameter of the IVC during expiration minus minimum diameter of the IVC during inspiration. A single investigator, blinded to randomisation and time of echocardiography, conducted all offline echocardiography parameter analyses using EchoPAC software BT 113 (GE Medical Systems Ultrasound, Norway).

\section{Neurological performance assessment}

Follow-up was performed 180 days after enrolment. The primary outcome was CPC at 180 days (CPC180). CPC180 was assessed at a telephone interview by a researcher blinded to the results of randomisation and echocardiography. The outcome was dichotomised, and CPC180 scores of 1 (no neurological deficit) and 2 (mild to moderate dysfunction) were characterised as good neurological outcome, and CPC scores 3 (severe dysfunction), 4 (coma), and 5 (death) were characterised as poor neurological outcome. Neurological prognostication and decisions on withdrawal of treatment in the ICU was made by doctors independent of the group of investigators and the trial.

\section{Statistical analysis}

Study population characteristics are presented as medians and interquartile ranges for continuous data and as absolute numbers and percentages for categorical values. The Student's $t$ test was used to compare continuous parametric values, the Chi-Square test for binary 
values, and the Mann-Whitney $U$ test was used for nonparametric variables. This study is a post-hoc analysis of data from the TTH48-trial; power calculations have thus not been performed prior to patient inclusion.

A multiple logistic regression adjusted for primary rhythm status, time to ROSC, and age was performed to test if each of the systolic and diastolic outcome measures at $24 \mathrm{~h}, 48 \mathrm{~h}$, and $72 \mathrm{~h}$ were associated with neurological outcome. To analyse the difference from $24 \mathrm{~h}$ to $72 \mathrm{~h}$ in the good and poor outcome group, a post hocanalysis using linear combinations of estimators was performed if the model fitted the data set. Further, a repeated measures mixed model with unstructured covariance was used to calculate medians of each echocardiographic parameter and to estimate the differences between the good and poor outcome groups over time for each echocardiography parameter. Echocardiography data is presented as means (95\% confidence intervals (CI)). Data was analysed using STATA 14 (StataCorp LP, TX, USA) and a $p$-value $<0.05$ was considered statistically significant. Our analysis was a post-hoc sub analysis of a previously published randomised controlled trial with multiple continuous independent echocardiographic variables and thus correction of $p$-values for multiple testing was not applied.

\section{Results}

Study population and baseline characteristics

Ninety-nine patients were included in the final study population and the selection process is shown in Fig. 1.

The study population is presented in Table 1. Fortyseven patients (47\%) were treated with TTM24 and 52 patients (53\%) were treated with TTM48 (Table 1). In the TTM24 group the mean time from ROSC to extubation was $68.9 \mathrm{~h}(n=32,95 \% \mathrm{CI}: 54.2-83.7)$, and in the TTM 48 group mean time from ROSC to extubation was $88.0 \mathrm{~h}(n=34,95 \% \mathrm{CI}: 75.9-100.0, p=0.05)$. At the 180-day follow-up across TTM-groups, 65 patients (66\%) had a good neurological outcome and 34 patients (34\%) had a poor neurological outcome (Table 1) with no difference between TTM groups. Patients with good outcome more often had a primary shockable rhythm $(p=0.03)$ and time from CA to ROSC was significantly shorter compared with patients with poor outcome

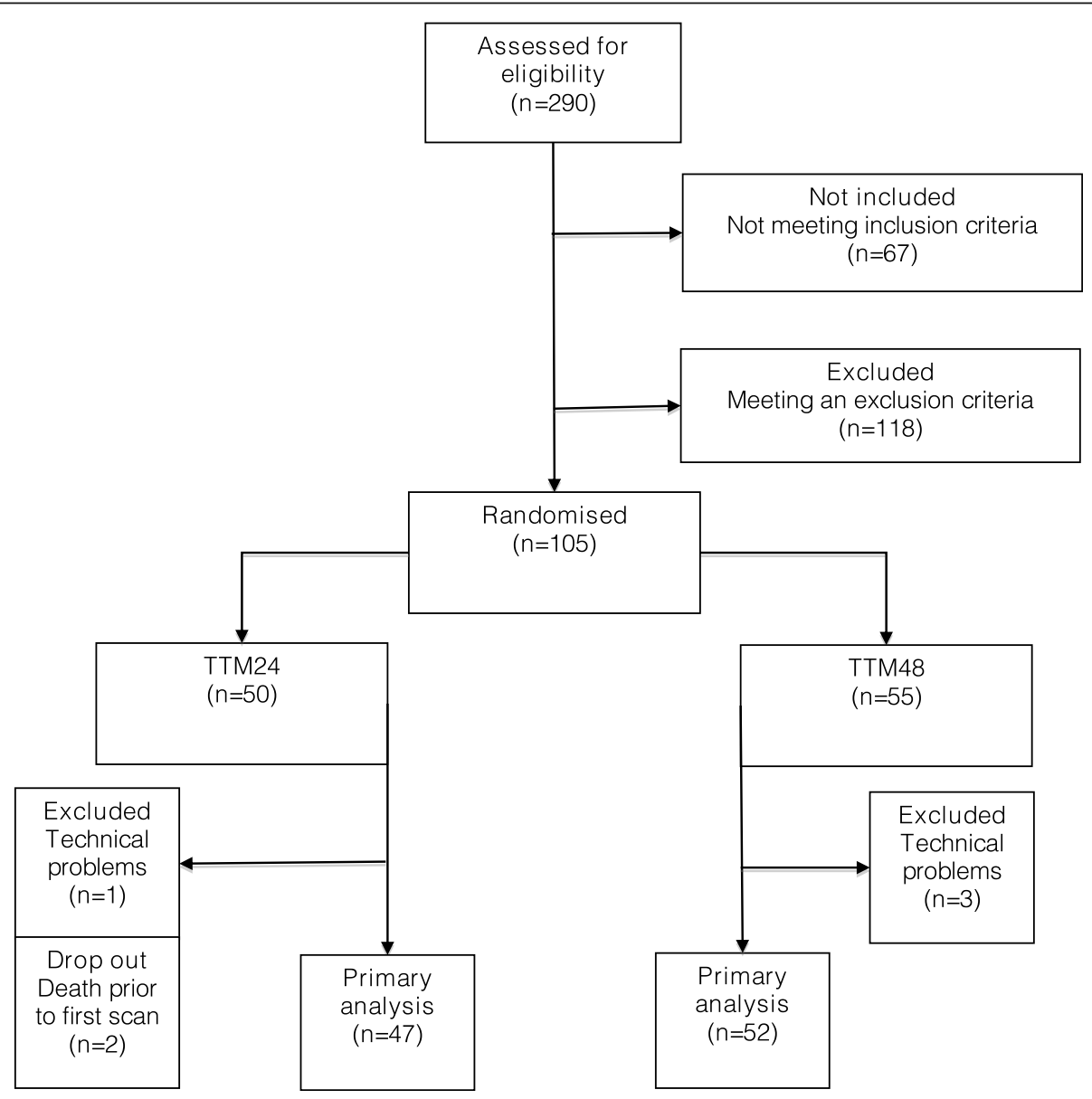

Fig. 1 Consort diagram. Technical problems indicate problems with poor image quality where outcomes were not assessable 
Table 1 Baseline characteristics.

\begin{tabular}{|c|c|c|c|}
\hline & Poor outcome & Good outcome & P-value \\
\hline Patients n (\%) & $34(34)$ & $65(66)$ & \\
\hline Age, years (median and IQR) & $63(58-70)$ & $59(53-68)$ & 0.05 \\
\hline Male n $(\%)$ & $29(85)$ & $58(89)$ & 0.57 \\
\hline Female n (\%) & $5(15)$ & $7(11)$ & \\
\hline \multicolumn{4}{|l|}{ Resuscitation } \\
\hline Bystander CPR performed n (\%) & $31(91)$ & $56(86)$ & 0.47 \\
\hline Primary shockable rhythm n (\%) & $22(65)$ & $62(95)$ & $<0.001$ \\
\hline No flow time minutes (median and IQR) & $1(0-1)$ & $1(0-1)$ & 0.74 \\
\hline Time to ROSC minutes (median and IQR) & $27(20-36)$ & $17(14-26)$ & 0.02 \\
\hline \multicolumn{4}{|l|}{ Admission } \\
\hline PCI performed n (\%) & $15(44)$ & $24(37)$ & 0.49 \\
\hline Lactate at arrival mmol/L (median and IQR) & $5(3-7)$ & $2(2-4)$ & $<0.001$ \\
\hline TNT at arrival & $108(59-323)$ & $125(47-222)$ & 0.97 \\
\hline Time from CA to TT (median and IQR) & $307(204-372)$ & $283(240-355)$ & 0.97 \\
\hline TTM-group & & & 0.63 \\
\hline TTM24 n (\%) & $15(44)$ & $32(49)$ & \\
\hline TTM48 n (\%) & $19(56)$ & $33(51)$ & \\
\hline \multicolumn{4}{|l|}{ Co-morbidities } \\
\hline Previous AMI n (\%) & $10(29)$ & $12(18)$ & 0.21 \\
\hline Diabetes Mellitus n (\%) & $9(26)$ & $8(12)$ & 0.08 \\
\hline Renal failure n (\%) & $5(15)$ & $8(12)$ & 0.74 \\
\hline Hypercholesterolaemia n (\%) & $13(38)$ & $22(34)$ & 0.66 \\
\hline Known IHD n (\%) & $13(38)$ & $14(22)$ & 0.08 \\
\hline Hypertension n (\%) & $19(56)$ & $30(46)$ & 0.36 \\
\hline Smokers & & & 0.97 \\
\hline Present n (\%) & $11(32)$ & $20(31)$ & \\
\hline Previous n (\%) & $11(32)$ & $21(32)$ & \\
\hline Never n (\%) & $7(21)$ & $16(25)$ & \\
\hline NA n $(\%)$ & $5(15)$ & $8(12)$ & \\
\hline Alcohol abuse n (\%) & $3(9)$ & $5(8)$ & 0.72 \\
\hline SAPS II (median and IQR) & $58(51-63)$ & $47(42-51)$ & $<0.001$ \\
\hline
\end{tabular}

Data are presented as medians (interquartile range) for continuous data and absolute numbers (\%) for binary data. Abbreviations: AMI Acute myocardial infarction, CA Cardiac arrest, CPC Cerebral performance category, CPR Cardiopulmonary resuscitation, IHD Ischemic heart disease, IQR Interquartile range, NA Not available, $P C I$ Percutaneous coronary intervention, ROSC Return of spontaneous circulation, SAPS Simplified acute physiology score, TNT Troponin T, $\Pi T$ Start of therapeutic temperature management, TTM Therapeutic temperature management

(Table 1). Arrival lactate and Simplified Acute Physiology Score II (SAPSII) were significantly lower among patients with good outcome compared with patients with poor outcome (Table 1).

\section{Left ventricular function}

Neither our primary outcome s' nor GLS and LVEF were associated with CPC180 across all three scan time points (Fig. 2, Additional file 1) or at each scan time point (Table 2, Fig. 2, Additional file 1). Estimated median e' at $48 \mathrm{~h}$ was significantly higher in patients with good neurological outcome compared with patients with poor neurological outcome $(p=0.044)$ (Fig. 2, Additional file 1).
However, when comparing changes over time, e' was not significantly different between patients with good and bad outcome, respectively (Fig. 2, Additional file 1). E/e' was not associated with neurological outcome neither at each time point nor across time points (Table 2, Fig. 2, Additional file 1). No parameter for left ventricular systolic or diastolic function showed significant differences when testing for parallel curves across all scan time points (Fig. 2, Additional file 1).

\section{Right ventricular function}

TAPSE was not associated with neurological outcome across any of the included parameters (Table 2, Fig. 2, 


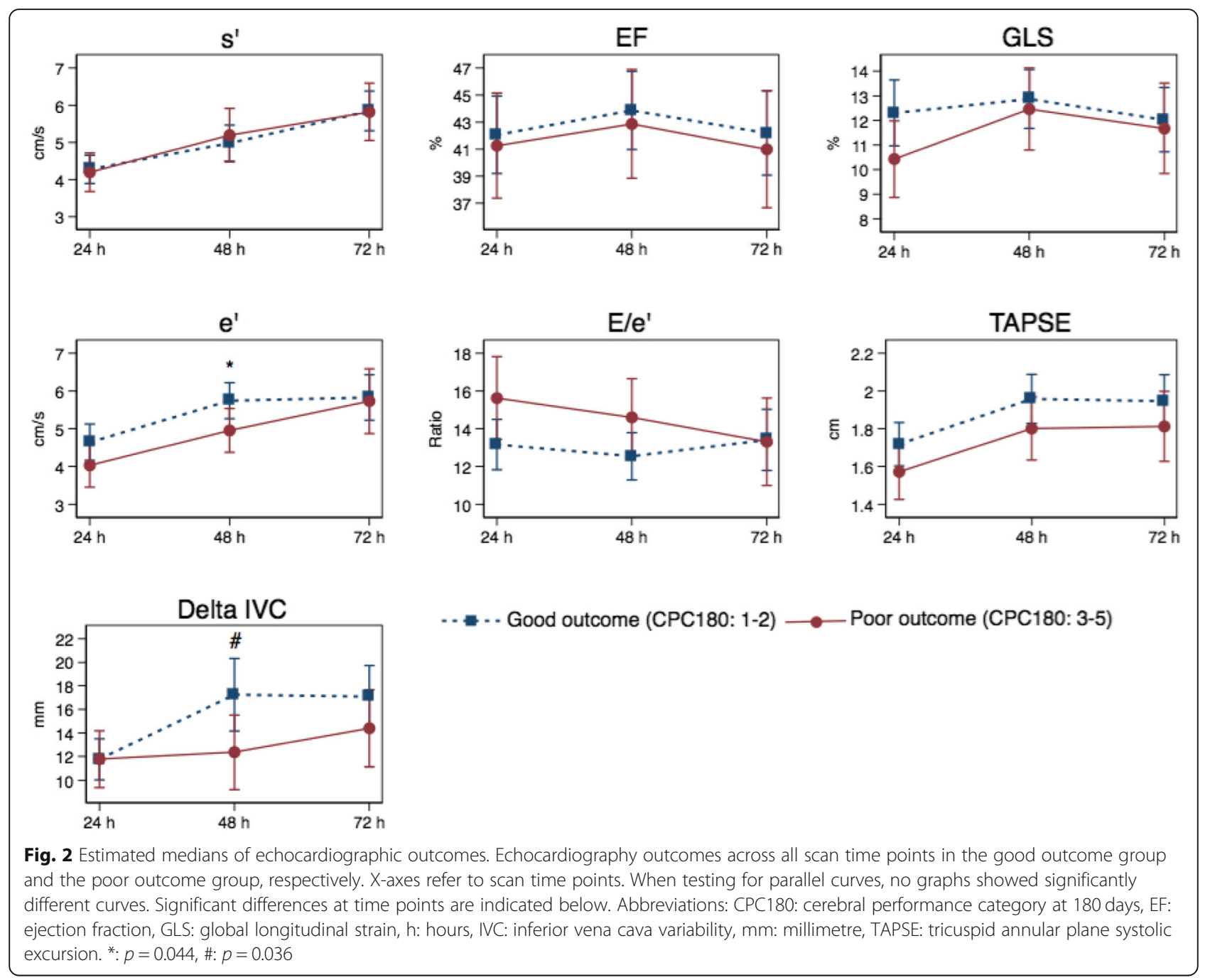

Additional file 1); however, higher $\triangle \mathrm{IVC}$ at $48 \mathrm{~h}$ predicted a poor neurological outcome (OR $0.95,95 \% \mathrm{CI}$ $0.910 ; 0.996, p=0.03$ ) (Table 2). Furthermore, the estimated median $\triangle \mathrm{IVC}$ at $48 \mathrm{~h}$ was significantly higher in patients with good outcome compared with patients with poor outcome $(p=0.036)$ (Fig. 2, Additional file 1). Neither TAPSE nor $\triangle I V C$ showed a significant result when testing for parallel curves across all scan time points (Fig. 2, Additional file 1).

\section{Discussion}

This study showed no association between s', global strain, LVEF, TAPSE, or E/e' acquired after reaching the target temperature and 180 days neurological outcome. No echocardiography parameter showed consistent differences across all scan time points.

\section{TTE evaluation of cardiac function}

In our study, e' and $\triangle \mathrm{IVC}$ at $48 \mathrm{~h}$ were the only TTE parameters associated with neurological outcome. The lower IVC variability found during hypothermia may reflect an elevated preload caused by diastolic dysfunction during hypothermia [32]. At $48 \mathrm{~h}$, the TTM48 group was still hypothermic and the TTM24 group was normothermic adding to random variation at this point. At $72 \mathrm{~h}$, more patients in the poor neurological outcome group were intubated and received positive pressure ventilation. Positive pressure ventilation is known to affect diastolic echocardiography parameters [33] and IVC dynamics [34]. Though not significant the duration of positive pressure ventilation was longer in the TTM48 group due to the prolonged cooling period compared with the TTM24 group. The prolonged positive pressure ventilation in the TTM48 group could be the reason for the lower e' and $\triangle \mathrm{IVC}$ at $48 \mathrm{~h}$. However, these individual comparisons were not adjusted for the number of analyses for each echocardiography variable. As previously mentioned, correction of $p$-values was not performed, as it was not found suitable for this post-hoc analysis and not necessary to elucidate that the significant $\mathrm{p}$-values in 
Table 2 Echocardiographic indices and neurological outcome.

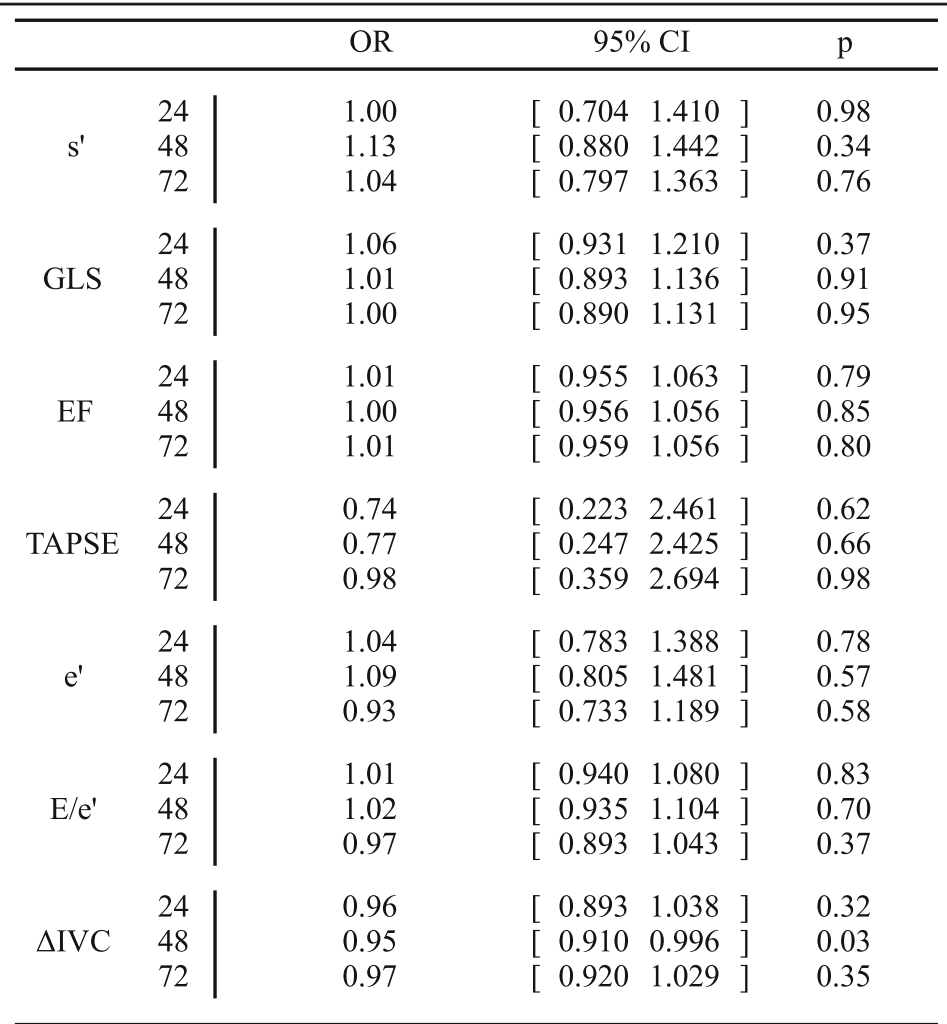

Multiple logistic regressions adjusted for primary rhythm, time to ROSC, and age. Higher OR depicts higher risk of poor outcome. The numbers 24,48 and 72 to the right of the variable refer to echocardiography acquired $24 \mathrm{~h}, 48 \mathrm{~h}$ and $72 \mathrm{~h}$ following the start of targeted temperature management. Abbreviations: $E F$ Ejection fraction, GLS Global longitudinal strain, IVC Inferior vena cava variability, OR Odds ratio, TAPSE Tricuspid annular plane systolic excursion, $95 \% \mathrm{Cl} 95 \%$ confidence interval

this study most likely represent type 1 errors. Only $\triangle \mathrm{IVC}$ and e' at $48 \mathrm{~h}$ turned out to be significantly different between the good and poor outcome group, but only at $48 \mathrm{~h}$ scan time and only $\triangle \mathrm{IVC}$ was associated to neurological outcome at this scan time. However all pvalues were remarkably close to 0.05 and the overall analyses for all echocardiography variables did not show any significant differences between groups and, hence as mentioned above, the significant differences at any individual time points are probably type 1 errors. A recent study found that low e' was associated with in-hospital death following OHCA [19]. Significantly more patients with poor outcome were, however, intubated and thus the results may be confounded by the effect of positive pressure ventilation on diastolic function [19].

We previously showed a beneficial effect of TTM48 on s' compared with TTM24; however, this effect was not seen across other echocardiography parameters [14]. Our study did not show an association between echocardiography measures of left ventricular systolic function and outcome. We included s' and GLS in our evaluation of left ventricular systolic function since these markers are less preload-dependent and more sensitive to changes in left ventricular function compared with
LVEF, especially following ischemia [23, 35-38]. In general, GLS may overestimate left ventricular function during ischaemia due to post-systolic shortening, adding to random variation [37]. However, as we defined the end of the systole as the closure of the aortic valve, postsystolic shortening should not have affected the GLS values included in this study. Heart rate increased during rewarming and may have affected speckle tracking and thus the GLS measurements [36].

Previously, we showed that s' improved in patients treated with TTM48 [14] although TTM48 did not improve neurological outcome compared with TTM24 [13]. s' was not associated with neurological outcome in our study, despite being highly reproducible and sensitive to changes in left ventricular systolic function and insensitive to poor image quality often encountered in intensive care patients [23, 39]. However, s' is angledependent and measurements may be affected by respiration [23, 33].

\section{Timing of TTE and clinical implications}

Our study evaluates the cooling and peri-rewarming phase during post-cardiac arrest TTM. PCAMD is present within the first hours following cardiac arrest 
and slowly recovers in the following days and months [4, 18]. LVEF, E/e' and right ventricular diameter assessed following cardiac arrest have been shown to be associated with mortality and neurological outcome [15-18, 20, 4042], though results are inconsistent [19, 43-45]. In studies showing an association between LVEF, E/e', and right ventricular function TTE was performed within the first $24 \mathrm{~h}$ of admission to hospital [15-18, 20, 40-42]. In this period, the immediate effects of acute ischaemia of the heart and affected ventricular function are more pronounced $[4,18]$. Patients in previous studies were heterogeneous and not comparable to our population with regard to lower rates of bystander CPR, longer times to ROSC, fewer patients had a primary shockable rhythm and survival rates were lower [15-18, 20, 40-42]. Patients in our study were immediately evaluated with coronary angiography and significant coronary lesions were treated. Thus, previous study populations have included more affected patients in the acute phase following cardiac ischaemia. Existing studies suggest that assessment of acute ischemia on left ventricular function has a greater potential of predicting neurological outcome compared with later scan times. However, the present study suggests that early serial TTE evaluation of cardiac function is not effective in prognosticating neurological outcome in the cooling and peri-rewarming phases following OHCA.

In our study, patients with good neurological outcome more often had a primary shockable rhythm, shorter times to ROSC, lower arrival lactate, and lower SAPSII scores (Table 1) indicating that prognostication of outcome following OHCA is a multimodal process including several clinical parameters [4]. Our data suggest that assessment of PCAMD on early serial TTEs following OHCA does not add important clinical value in prognostication of neurological outcome following cardiac arrest.

\section{Limitations}

Our study has certain strengths as opposed to previous studies. We present results based on standardised early serial TTE scan times in a well-defined population of comatose OHCA patients. Standardised scan times were utilised to ensure comparability between data. Thus, our design enabled assessment of changes in TTE parameters over time and not only at single time point estimates. Few and experienced doctors performed all echocardiographies. One person blinded to patient treatment and outcome did the offline analyses, and interand intra-observer variability have previously been shown to be low [14]. Nonetheless, the process of patient inclusion in this study may have been subject to selection bias. Written consent was obtained from a legal next of kin following admission, which may have delayed randomisation slightly and, hence, the most ill patients may have been lost before study enrolment. As cardiac death often occurs early, this may have impacted on our results. In contrast to previous studies $[19,20]$, we excluded patients in prolonged cardiogenic shock, thus our selection process has probably favoured a population less ill compared to previous studies. Patients with good outcome more often had a primary shockable rhythm and were less likely to be diagnosed with diabetes (Table 1). Due to the number of patients in our analysis, we decided to adjust for a maximum of three variables (primary rhythm, time to ROSC and age). The rate of bystander CPR of $88 \%$ in our population was higher compared with previous studies $[15,19,20,46]$, but is comparable to the rate of bystander CPR reported in the TTM trial [47]. Only 34 patients had a poor neurological outcome limiting multivariate analysis and mixed model analysis in each group. Our analysis was a post-hoc analysis and power calculations have thus not been performed; type 2 error was a risk.

The scan time points in our study were standardised during cooling and rewarming. In an effort to limit missing data, three scan time points were chosen and thus, the TTM24 group had two scans during rewarming while the TTM48 group only had one. Comparing different rewarming periods may have added random variation to our results.

\section{Conclusion}

Our study showed no consistent significant association between s', GLS, LVEF, e', E/e', TAPSE or $\triangle I V C$ on early serial TTEs and 180-day neurological outcome in comatose survivors of OHCA. This study suggests that early serial TTE parameters in comatose survivors of OHCA are ineffective in predicting neurological outcome and do not add significant value to the already established prognostic process following OHCA.

\section{Supplementary Information}

The online version contains supplementary material available at https://doi. org/10.1186/s13049-021-00849-7.

Additional file 1:. Estimated medians of each echocardiographic

outcome measure at each scan time point.

\section{Abbreviations}

CPC180: Cerebral Performance Category; e': Peak diastolic mitral valve annular velocity; E: Early diastolic mitral blood flow; TAPSE: Tricuspid annular plane systolic excursion; GCS: Glasgow coma score; GLS: Global longitudinal strain; h: Hours; ICU: Intensive care unit; ILCOR: International Liaison Committee on Resuscitation; IVC: Inferior vena cava variability; LVEF: Left ventricular ejection fraction; OHCA: Out-of-hospital cardiac arrest; PCAM D: Post-cardiac arrest myocardial dysfunction; ROSC: Return of spontaneous circulation; s': Peak systolic mitral valve annular velocity; SAPSIl: Simplified Acute Physiology Score II; TTE: Transthoracic echocardiography; TTH48: The Targeted Temperature Management for 48 vs. 24 Hours and Neurologic Outcome After Out-of-Hospital Cardiac Arrest Trial; TTM: Targeted temperature management 


\section{Acknowledgements}

We sincerely thank Marianne Godt Hansen for reviewing the final manuscript and providing linguistic assistance.

\section{Authors' contributions}

$H K, A M G, C H V D$ and ANJ contributed to the design of the temperature management and randomisation protocol. AMG and THJ conceived the design of the statistical analysis. AMG, PJO, JH, CAF and BRRN participated in acquisition of echocardiographic data. THJ performed statistical analyses with assistance from AMG, PJO and CHVD. THJ drafted the manuscript with substantive revision from AMG and PJO. All authors have read and approved the final manuscript.

\section{Authors' information}

Listed in the headline page.

\section{Funding}

Aarhus University, Central Denmark Region, Aase and Ejnar Danielsens Foundation, Danish Society of Anaesthesiology and Intensive Care Medicine, the Lily Benthine Lund's Foundation, Foundation of 1870, Foundation of 1.8.1978, and Raimond and Dagmar Ringgaard-Bohns Foundation supported the study financially. Financial contributors had no influence on study design, randomisation, data acquisition, analyses, the writing of the manuscript or choice of publishing journal.

\section{Availability of data and materials}

The datasets used and analysed during the current study are available from the corresponding author on reasonable request.

\section{Ethics approval and consent to participate}

The study was conducted according to the Declaration of Helsinki and approved by the Danish Health Research Ethics Committee (file number 20110022). Patients were enrolled after written informed consent from a legal next of kin and the patient's general practitioner.

\section{Consent for publication}

Not applicable.

\section{Competing interests}

AMG declares to have received speaking fee from Novartis and Merck Sharp and Dome (MSD). All other authors declare no conflicts of interest.

\section{Author details}

'Department of Cardiology, Viborg Regional Hospital, Heibergs Alle 2K, 8800 Viborg, Denmark. ${ }^{2}$ Department of Anaesthesiology and Intensive Care, Aarhus University Hospital, Aarhus, Denmark. ${ }^{3}$ Department of Cardiology, Aarhus University Hospital, Aarhus, Denmark. ${ }^{4}$ Centre of Head and Orthopaedics Rigshospitalet, Copenhagen, Denmark. ${ }^{5}$ Department of Otorhinolaryngology, Head and Neck Surgery, Aarhus University Hospital, Aarhus, Denmark. ${ }^{6}$ Department of Anaesthesiology, Regional Hospital West Jutland, Herning, Denmark. ${ }^{7}$ Research Center for Emergency Medicine, Aarhus University Hospital, Aarhus, Denmark.

\section{Received: 8 November 2020 Accepted: 5 February 2021}

\section{Published online: 19 February 2021}

\section{References}

1. Benjamin EJ, Blaha MJ, Chiuve SE, et al. Heart disease and stroke Statistics2017 update: a report from the American Heart Association. Circulation. 2017;135:e146-603.

2. Berdowski J, Berg RA, Tijssen JG, Koster RW. Global incidences of out-ofhospital cardiac arrest and survival rates: systematic review of 67 prospective studies. Resuscitation. 2010;81:1479-87.

3. Dragancea I, Rundgren M, Englund E, Friberg H, Cronberg T. The influence of induced hypothermia and delayed prognostication on the mode of death after cardiac arrest. Resuscitation. 2013:84:337-42.

4. Nolan JP, Neumar RW, Adrie C, et al. Post-cardiac arrest syndrome: Epidemiology, pathophysiology, treatment, and prognostication: A scientific statement from the International Liaison Committee on Resuscitation; the American Heart Association Emergency Cardiovascular Care Committee; the Council on Cardiovascular Surgery and Anesthesia; the Council on
Cardiopulmonary, Perioperative, and Critical Care; the Council on Clinical Cardiology; the Council on Stroke (Part 1). Int Emerg Nurs. 2009;17:203-25.

5. Laurent I, Monchi M, Chiche JD, et al. Reversible myocardial dysfunction in survivors of out-of-hospital cardiac arrest. J Am Coll Cardiol. 2002:40:2110-6.

6. Gazmuri RJ, Weil MH, Bisera J, Tang W, Fukui M, McKee D. Myocardial dysfunction after successful resuscitation from cardiac arrest. Crit Care Med. 1996;24:992-1000

7. Cha KC, Kim HI, Kim OH, et al. Echocardiographic patterns of postresuscitation myocardial dysfunction. Resuscitation. 2018;124:90-5

8. Kern KB, Hilwig RW, Rhee KH, Berg RA. Myocardial dysfunction after resuscitation from cardiac arrest: an example of global myocardial stunning. J Am Coll Cardiol. 1996;28:232-40.

9. Perkins GD, Jacobs IG, Nadkarni VM, et al. Cardiac Arrest and Cardiopulmonary Resuscitation Outcome Reports: Update of the Utstein Resuscitation Registry Templates for Out-of-Hospital Cardiac Arrest: A Statement for Healthcare Professionals From a Task Force of the International Liaison Committee on Resuscitation (American Heart Association, European Resuscitation Council, Australian and New Zealand Council on Resuscitation, Heart and Stroke Foundation of Canada, InterAmerican Heart Foundation, Resuscitation Council of Southern Africa, Resuscitation Council of Asia); and the American Heart Association Emergency Cardiovascular Care Committee and the Council on Cardiopulmonary, Critical Care, Perioperative and Resuscitation. Resuscitation. 2015;96:328-40.

10. Bernard SA, Gray TW, Buist MD, et al. Treatment of comatose survivors of out-of-hospital cardiac arrest with induced hypothermia. N Engl J Med. 2002;346:557-63.

11. GROUP THACAS. Mild therapeutic hypothermia to improve the neurologic outcome after cardiac arrest. N Engl J Med. 2002;346:549-56.

12. Donnino MW, Andersen LW, Berg KM, et al. Temperature management after cardiac arrest: an advisory statement by the advanced life support task force of the international liaison committee on resuscitation and the American Heart Association emergency cardiovascular care committee and the council on cardiopulmonary, critical care, perioperative and resuscitation. Resuscitation. 2016;98:97-104.

13. Kirkegaard H, Soreide $\mathrm{E}$, de Haas I, et al. Targeted temperature management for 48 vs 24 hours and neurologic outcome after out-of-hospital cardiac arrest: a randomized clinical trial. Jama. 2017;318:341-50.

14. Grejs AM, Nielsen BRR, Juhl-Olsen P, et al. Effect of prolonged targeted temperature management on left ventricular myocardial function after outof-hospital cardiac arrest - a randomised, controlled trial. Resuscitation. 2017; 115:23-31.

15. Anderson RJ, Jinadasa SP, Hsu L, et al. Shock subtypes by left ventricular ejection fraction following out-of-hospital cardiac arrest. Crit Care. 2018;22: 162.

16. Chang WT, Ma MH, Chien KL, et al. Postresuscitation myocardial dysfunction: correlated factors and prognostic implications. Intensive Care Med. 2007;33:88-95.

17. Checchia PA, Sehra R, Moynihan J, Daher N, Tang W, Weil MH. Myocardial injury in children following resuscitation after cardiac arrest. Resuscitation. 2003;57:131-7.

18. Ruiz-Bailen M, Aguayo de Hoyos E, Ruiz-Navarro S, et al. Reversible myocardial dysfunction after cardiopulmonary resuscitation. Resuscitation. 2005;66:175-81

19. Jentzer JC, Anavekar NS, Mankad SV, et al. Echocardiographic left ventricular diastolic dysfunction predicts hospital mortality after out-of-hospital cardiac arrest. J Crit Care. 2018:47:114-20.

20. Jentzer JC, Anavekar NS, Mankad SV, et al. Changes in left ventricular systolic and diastolic function on serial echocardiography after out-ofhospital cardiac arrest. Resuscitation. 2018;126:1-6.

21. Grossestreuer AV, Abella BS, Sheak KR, et al. Inter-rater reliability of post-arrest cerebral performance category (CPC) scores. Resuscitation. 2016;109:21-4.

22. Nikitin NP, Witte KK, Thackray SD, de Silva R, Clark AL, Cleland JG. Longitudinal ventricular function: normal values of atrioventricular annular and myocardial velocities measured with quantitative two-dimensional color Doppler tissue imaging. J Am Soc Echocardiography. 2003;16:906-21.

23. Mor-Avi V, Lang RM, Badano LP, et al. Current and evolving echocardiographic techniques for the quantitative evaluation of cardiac mechanics: ASE/EAE consensus statement on methodology and indications endorsed by the Japanese Society of Echocardiography. Eur J Echocardiography. 2011;12:167-205. 
24. Stanton T, Marwick TH. Assessment of subendocardial structure and function. J Am Coll Cardiol Img. 2010;3:867-75.

25. Husebye T, Eritsland J, Bjørnerheim R, Andersen G. Systolic mitral annulus velocity is a sensitive index for changes in left ventricular systolic function during inotropic therapy in patients with acute heart failure. Eur Heart J Acute Cardiovasc Care. 2018;7:321-9.

26. Biering-Sørensen T, Jensen JS, Pedersen $S$, et al. Doppler tissue imaging is an independent predictor of outcome in patients with ST-segment elevation myocardial infarction treated with primary percutaneous coronary intervention. J Am Soc Echocardiography. 2014;27:258-67.

27. Mogelvang R, Sogaard P, Pedersen SA, et al. Cardiac dysfunction assessed by echocardiographic tissue Doppler imaging is an independent predictor of mortality in the general population. Circulation. 2009;119:2679-85.

28. Yamamoto T, Oki T, Yamada H, et al. Prognostic value of the atrial systolic mitral annular motion velocity in patients with left ventricular systolic dysfunction. J Am Soc Echocardiography. 2003;16:333-9.

29. Kirkegaard H, Rasmussen BS, de Haas I, et al. Time-differentiated target temperature management after out-of-hospital cardiac arrest: a multicentre, randomised, parallel-group, assessor-blinded clinical trial (the TTH48 trial): study protocol for a randomised controlled trial. Trials. 2016;17:228.

30. Cummins RO, Chamberlain DA, Abramson NS, et al. Recommended guidelines for uniform reporting of data from out-of-hospital cardiac arrest: the Utstein style. A statement for health professionals from a task force of the American Heart Association, the European resuscitation council, the Heart and Stroke Foundation of Canada, and the Australian resuscitation council. Circulation. 1991;84:960-75.

31. Sessler CN, Gosnell MS, Grap MJ, et al. The Richmond agitation-sedation scale: validity and reliability in adult intensive care unit patients. Am J Respir Crit Care Med. 2002;166:1338-44.

32. Polderman $\mathrm{KH}$. Mechanisms of action, physiological effects, and complications of hypothermia. Crit Care Med. 2009;37:S186-202.

33. Juhl-Olsen P, Hermansen JF, Frederiksen CA, Rasmussen LA, Jakobsen CJ Sloth E. Positive end-expiratory pressure influences echocardiographic measures of diastolic function: a randomized, crossover study in cardiac surgery patients. Anesthesiology. 2013;119:1078-86.

34. Rudski LG, Lai WW, Afilalo J, et al. Guidelines for the echocardiographic assessment of the right heart in adults: a report from the American Society of Echocardiography endorsed by the European Association of Echocardiography, a registered branch of the European Society of Cardiology, and the Canadian Society of Echocardiography. J Am Soc Echocardiography. 2010;23:685-713 quiz 786-8.

35. Andersen NH, Terkelsen CJ, Sloth E, Poulsen SH. Influence of preload alterations on parameters of systolic left ventricular long-axis function: a Doppler tissue study. J Am Soc Echocardiography. 2004;17:941-7.

36. Dandel M, Lehmkuhl H, Knosalla C, Suramelashvili N, Hetzer R. Strain and strain rate imaging by echocardiography - basic concepts and clinical applicability. Curr Cardiol Rev. 2009;5:133-48.

37. Smiseth OA, Torp H, Opdahl A, Haugaa KH, Urheim S. Myocardial strain imaging: how useful is it in clinical decision making? Eur Heart J. 2016;37:1196-207.

38. Vermeiren GL, Malbrain ML, Walpot JM. Cardiac Ultrasonography in the critical care setting: a practical approach to asses cardiac function and preload for the "non-cardiologist". Anaesthesiol Intensive Ther. 2015;47:s89-104.

39. Fraser AG, Payne N, Madler CF, et al. Feasibility and reproducibility of off-line tissue Doppler measurement of regional myocardial function during dobutamine stress echocardiography. Eur J Echocardiography. 2003;4:43-53.

40. Conlon TW, Falkensammer CB, Hammond RS, Nadkarni VM, Berg RA, Topjian AA. Association of left ventricular systolic function and vasopressor support with survival following pediatric out-of-hospital cardiac arrest. Pediatr Crit Care Med. 2015;16:146-54.

41. Ramjee V, Grossestreuer AV, Yao Y, et al. Right ventricular dysfunction after resuscitation predicts poor outcomes in cardiac arrest patients independent of left ventricular function. Resuscitation. 2015;96:186-91.

42. Wardi G, Blanchard D, Dittrich T, Kaushal K, Sell R. Right ventricle dysfunction and echocardiographic parameters in the first $24 \mathrm{~h}$ following resuscitation in the post-cardiac arrest patient: a retrospective cohort study. Resuscitation. 2016;103:71-4.

43. Burstein B, Jayaraman D, Husa R. Early left ventricular ejection fraction as a predictor of survival after cardiac arrest. Acute Card Care. 2016;18:35-9.

44. Jentzer JC, Chonde MD, Shafton A, et al. Echocardiographic left ventricular systolic dysfunction early after resuscitation from cardiac arrest does not predict mortality or vasopressor requirements. Resuscitation. 2016;106:58-64.
45. Yao Y, Johnson NJ, Perman SM, Ramjee V, Grossestreuer AV, Gaieski DF. Myocardial dysfunction after out-of-hospital cardiac arrest: predictors and prognostic implications. Intern Emerg Med. 2018;13:765-72.

46. Wissenberg $M$, Lippert FK, Folke F, et al. Association of national initiatives to improve cardiac arrest management with rates of bystander intervention and patient survival after out-of-hospital cardiac arrest. Jama. 2013;310: 1377-84.

47. Nielsen N, Wetterslev J, Cronberg T, et al. Targeted temperature management at 33 degrees $C$ versus 36 degrees $C$ after cardiac arrest. N Engl J Med. 2013;369:2197-206.

\section{Publisher's Note}

Springer Nature remains neutral with regard to jurisdictional claims in published maps and institutional affiliations.
Ready to submit your research? Choose BMC and benefit from:

- fast, convenient online submission

- thorough peer review by experienced researchers in your field

- rapid publication on acceptance

- support for research data, including large and complex data types

- gold Open Access which fosters wider collaboration and increased citations

- maximum visibility for your research: over $100 \mathrm{M}$ website views per year

At BMC, research is always in progress.

Learn more biomedcentral.com/submissions 